\title{
Preface to the 2013 printing
}

This is a new printing of the book, not a new edition. The reason is that the main thrust of the argument put forward in the book has been unaffected by recent historical events. We still see that there are global problems that cannot be handled on any other level than the global one. This is true in particular of problems to do with war and peace, global injustices and global warming. Here we also see that a reaction to the fact is increased global governance, on an ad hoc basis.

Little has happened in relation to war and peace since the first printing. It is of note, however, that when I claim that the relatively peaceful time, in which we now happen to live, may quickly come to an end, once big powers engage again in third world (civil) wars, the situation in Syria bears witness to what may come.

The global injustices are roughly as they were at the time of the first printing of this book. It seems obvious that we cannot obviate them, unless we resort to global political measures.

The problem with global warming seems even more acute now than it appeared to be only a few years ago. But the development in this field is so quick that in the present context there is little reason to try to keep track of all new emerging data corroborating the claim that we need to move to a global level in our search of solutions. Here we also see signs that global governance is what in fact will be resorted to. The World Bank is now engaged in the matter!

There is no denying that we are moving in the direction of global governance; the local democracies wither under the pressure from globalisation. However, there is little sign that we are moving in the direction of global democracy. The main message of the book is that this is both possible and desirable, however. And there are a few optimistic signs to the effect that many have come to recognise that, unless we turn go global democracy, we will soon find ourselves ruled by a global dictatorship. There was a time when only people 


\section{Global democracy}

in the 'lunatic fringe' (I was one of them) thought of themselves as citizens of the world. Now we see authoritative and hopeful initiatives taking place such as the Campaign for a United Nations Parliamentary Assembly: http:/ / en.unpacampaign.org/index.php

Torbjörn Tännsjö

June 2013 